\title{
THE BIOGRAPHY OF OBJECTS
}

\author{
C. Greco* \\ (Keynote) \\ Museo Egizio, Torino. Via Accademia delle Scienze 6, 10123 Torino, Italy - christian.greco@museoegizio.it
}

KEY WORDS: biography of objects, digital revolution, humanism, cognitive process, multidisciplinary approach, museums

\begin{abstract}
:
Today we find ourselves immersed in what is called the digital revolution, which has already profoundly transformed our cognitive approach and working methods. In archaeology, photogrammetry and 3D modelling enable archaeologists to document the whole excavation process and reconstruct contexts even after they have been removed. We can reproduce a coffin with sub-millimetric accuracy by recording all its phases of production and reuse. Non-invasive diagnostic imaging enables us to peer inside a still sealed vessel and virtually unwrap the mummies. Accurate analysis now gives scholars the opportunity to observe the fibres of a papyrus, helping us recompose ancient documents. Then digital communication enables us to create virtual working environments in which scholars from all over the world can confer and compare their data. All this facilitates and accelerates the work of scholars.

Does this mean that the humanist's role is becoming secondary? Quite the contrary. The data we glean is increasingly detailed and complex and requires an even greater level of interpretation. The scientist and the humanist have to work together even more closely to try and unravel the complexity of the contemporary world. This increasing collaboration goes beyond the dogmatisms of individual knowledge. The definition of a shared semantics and the development of a true multidisciplinary approach are the only method we have to cope with the challenges of the future.

And in all this, what will the role of the museum be? Are these institutions destined to disappear? The changes will continue. We will think of different organisational and architectural solutions responding to contemporary needs. There will certainly also be new forms of cultural enjoyment. Our task, however, will always be to improve the visual, aesthetic and intellectual experience of every visitor who comes face to face with a piece of the past, and to provide all the information necessary to enrich their understanding. So the future of museums is, as it has always been, research.
\end{abstract}

\section{DIGITAL REVOLUTION AND HUMANISM}

The There is an interdependence between human beings and the material culture they produce. The objects they create survive them and remain evidence of their lives, habits and relationships. The task of an archaeologist is to reconstruct the usages and customs of the ancients on the basis of their material culture. To do this, it is essential to investigate each artefact to try and understand its biography in depth.

Each object embodies a wealth of information. First of all we can try to place it in a time frame and seek to understand where it comes from and what its function was. However, analysis cannot stop at this level. The artefact contains a series of 'hidden' clues that enable us to find the answers to a whole series of questions. I like to recall, as does Ian Hodder at the beginning of his book Entangled (in which he analyses the close relationship between human beings and objects), the definition that Martin Heidegger gave of jar, in his work Poetry, Language and Thought of 1971 (Hodder, 2012; Heidegger, 1971).

There is, in fact, a certain dissatisfaction in merely giving a description of a vase, indicating its chronology and identifying its typology. When we think of its function, we understand that it is essential to know what liquid it held. The substance might have been oil, beer, wine or simply water. Sometimes the contents were used in a ritual context, for example to perform a libation to the gods. It could therefore be affirmed that the jar can be studied as a connecting element between the earth, as it is made of clay, men, since they created it, and the heavens, because it could be used in a religious ritual.
Now, modern archaeometric analyses can help us to answer many of the questions that crop up when we study an ancient container. Sometimes already autopsic analysis or diagnostic imaging enable us to discover highly interesting details, such as the presence of the fingerprints of the artist that modelled the object. Isotope investigations allow us to understand what type of clay was used and even determine where it came from. Analysis of the residue may provide us with clues to the last liquid contained in a vase. So that, by gathering all this information, the object gradually reveals its history, enables us to reconstruct its biography and becomes the instrument of interpretation to understand the habits and customs of the ancients (Miller, 2005).

Yet, to consider the artefact as a mere historical document, as the surviving witness to a distant and vanished world, does not do full justice to its value. When we visit a museum and admire an artefact kept in a display case, we establish a relationship with it that goes beyond the testimony to the world to which it belonged. Such an object, is given a new 'life' in the present. It is admired, studied, classified, interpreted and acquires a value that is probably very different from what it had in the past. An ancient Egyptian sarcophagus was certainly not created to be displayed in a glass case and admired as an art object.

Hence this second life, conducted in the museum, also has its value and must be analysed and studied. We could say that in reconstructing the biography of the archaeological object we should not forget that it was forgotten and lost. Sometimes it may have been reused for different tasks and purposes, then rediscovered in archaeological excavations, was restored to a

\footnotetext{
* Corresponding author
} 
new life and now it performs its function within a museum display.

So to reconstruct the biography of an artefact kept in a museum, we should not forget the value of the archives that document the history of its acquisition on the antiquarian market or its archaeological discovery, as well as the importance it may have had in the history of this intellectual discipline and the interest it has aroused among scholars and the civil community in general. An examination of the publications and an analysis of the results of the studies conducted by those who in the recent and distant past have devoted themselves to the comprehension of the above-mentioned object enable us to understand another fundamental point, namely the way research is constantly evolving.

Great scholars of the past, those who first succeeded in deciphering the language of the ancient Egyptians, for example, had insights, were able to grasp in depth the significance of a specific finding and their conclusions remain valid. Meanwhile, new discoveries, different observations, and a change in point of view have sometimes led us to alter our conclusions (Meskell, 2004).

Research teaches us to constantly question our results in an attempt to understand the ancient world thoroughly and to understand more about ourselves. The study of a past civilization in depth entails the analysis of historical events, the interpretation of written sources and archaeological data, a study of the society, of the economic, social and political organisation, administration, the evolution of thought, theology and rituality bound up with the cult of the supernatural, conceptions of life after death and considerations on the transience of human existence.

Archaeology has brought to light settlements that allow us to discover human activities from thousands of years ago. We are all indebted to this past history and one outcome of it. Our own biological structure, our technology, the structure of society and contemporary culture, even our cognitive method and our psychology, derive from the past. Historical awareness and the study of ancient civilisations are therefore essential to understanding our role in the present (Renfrew, 2016).

\section{NATURE OF OBJECTS, MATERIALS AND COGNITIVE FACTORS}

What is the nature of objects? They are certainly interconnected with each other and with human beings, but what are their characteristics and how can we define them and become aware of them? Studies on material culture lead us back to Hegel's Phenomenology of the Spirit (1807). By describing the direct relationship between subject and object, the German philosopher enables us to understand that humanity needs objects to understand itself. The indefinite subject becomes aware of its nature by understanding that there is a reality that is different from itself. Self-awareness is achieved by creating 'the other or the object'. Thus the subject is defined in relation to the object, something, therefore, opposed to it.

This first cognitive level, however, leads to dissatisfaction and the subject tends to reincorporate the object within itself, a phenomenon that Hegel termed 'sublation'. In this way new transcendent and collective forces such as society, law, religion, which tend to form 'the universal' are identified. The objectification described by Hegel is the process by which we create the world and define ourselves. This implies that there is no static subject-object contrast but a dialectical relationship in continuous evolution.

Can we also say that objects are endowed with a certain 'agency', a term that defines a category widely used in archaeology and anthropology to define the role of the individual in promoting change? Not the primary conscious agency typical of human intentionality but another kind attributed to them by humans? Artefacts exert over us a fascination, such as their duration, which brings us into contact with 'the other', the 'different' from us. This is then increased by knowledge. We could therefore say that the agency of artefacts is defined by their intrinsic characteristics and the way we perceive and imagine them (Dobres, Robb, 2009).

As mentioned above, studies of material culture increasingly tend to relate objects to their historical, archaeological context and the biographies of artefacts enable us to explore cultural relations and define variations in social structures. Thus, in some cases, as in the history of ancient Egypt, we are able to reconstruct the lives and roles played by the people who lived in the distant past only thanks to the objects and examples of the material culture that have come down to us. In this case, the subject's dependence on the object becomes clearly evident.

In reality, all through our cognitive process, we have to mitigate the fictitious opposition between conscious subject and inert object. The dependence on material culture is explicitly seen when, for example, we wish to formulate complex calculations and we therefore have recourse to paper and pen or calculators and computers. To construct memory and recollection we also use material means that enable us to store data. Sometimes, as Malafouris has shown, it becomes truly a complex matter to make a clear distinction between subject and object in the cognitive process (Malafouris, 2013; Malafouris, Renfrew 2010).

If we think of a blind person who is capable of having a perception of the world that surrounds him, and acquire mobility thanks to a white stick, where can we say that the perception of himself as opposed to the other begins? At the end of the hand or of the stick? The interconnection between 'things' and humans is truly pervasive and in a constant relationship of mutual influence. Our own biological and cognitive structure is influenced by material culture and for this reason we have to commit ourselves to studying the relationship between body, mind and artefacts. Despite the fact that this awareness is widespread, there remains a distance to be bridged between the human and the natural sciences.

The humanists, in fact, while stressing that the relationship and interconnection between subject and object is essential to the understanding of history, tend to adopt a humancentric approach and in studies of the agency of material culture, phenomenology and cognitive archaeology, they pay little attention to the materiality of the object. Archaeometers, on the other hand, record all the morphological characteristics of objects by studying their chemical and physical features.

If the humanists, therefore, focus on the social and historical processes by which material culture is produced and influences human existence, while natural scientists give us an exact account of the intrinsic characteristics of objects, we run the risk of undertaking the study of artefacts via two parallel and non-communicating paths. Coming to a composition between these two approaches is absolutely necessary if we are to understand the complexity of human history and the world that surrounds it. Humanists have to involve the archaeometers in defining the theoretical framework that defines studies of material culture; and natural scientists, at the same time, should realize that the role of the humanists is fundamental to fully understanding the interdependence between human beings and artefacts.

The archaeologist, anthropologist, historian, philosopher, neuroscientist, psychologist and social scientist need to work side by side with the chemist, physicist and computer expert to 
arrive at a definition of a new semantics that will enable us to understand the complexity of reality.

\section{THE STUDY OF THE PAST AND MODERN METHODS OF INVESTIGATION}

'Writing, Phaedrus, has this strange quality, and is very like painting; for the creatures of painting stand like living beings, but if one asks them a question, they preserve a solemn silence. And so it is with written words; you might think they spoke as if they had intelligence, but if you question them, wishing to know about their sayings, they always say only one and the same thing. And every word, when once it is written, is bandied about, alike among those who understand and those who have no interest in it, and it knows not to whom to speak or not to speak; when illtreated or unjustly reviled it always needs its father to help it; for it has no power to protect or help itself' (Plat. Phaedrus 275d-e).

In the course of human history there have been various phases when significant changes and important innovations have led us to rethink our cognitive systems and research methods. The defence of the spoken word made by Socrates in Athens in the late 5th BCE century is certainly significant.

The philosopher held that writing might hamper discourse and would lack the hermeneutical possibility guaranteed by the maieutic method that Socrates said he had learned from his mother Phaenarete, a midwife. As a woman, she facilitated childbirth, helping mothers to bear their children. Likewise the philosopher, by not imposing anything but prompting thought with compelling and probing questions, guided his interlocutor to discover the truth.

We know that the written culture became the dominant one and despite the strenuous defence of orality it was precisely the Platonic dialogues that consecrated the Socratic doctrine and transmitted his ideas to posterity. Clearly the advent of writing as the dominant mode for the transmission of knowledge opened up a range of possibilities and led to cognitive variations and modifications of important aspects of human life, such as memory.

It was no longer necessary to remember thousands of verses from epic poems, for example, since matter, as we have seen above, gave us the opportunity to record data and consult it when needed. However, every radical change requires serious reflection and deep study to grasp the opportunities it offers us and understand at the same time how our research methods may be influenced by it. Sometimes expectations are not met. There is often a tendency to repose great confidence in technical and scientific innovations, thinking that they can quickly solve all the scientific issues and problems that have not yet been answered (Vegetti, 2018).

In this respect, it is really interesting to observe how the discovery of one of the most important technological innovations of the 19th century was announced. On 7 January 1839, the scholar and politician François Jean Dominique Arago explained in detail to the French Academy the invention of Louis Mandé Daguerre, the daguerreotype, as 'a method for fixing the images that are painted by sun inside the camera obscura'. Arago himself presented a bill to the Chamber of Deputies in Paris on 15 June 1839. Re-reading part of the text we see how a whole series of possibilities is linked to this new

\footnotetext{
${ }^{1}$ English translation from www.perseus.tufts.edu (retrieved in April
} 2019). discovery, which would have allowed the progress of technical scientific research and improved knowledge of the world:

'Gentlemen, we believe we must anticipate the will of Parliament by proposing to acquire, in the name of the state, the ownership of a discovery which is as useful as it is unexpected and which it is important and in the interest of the arts and sciences to be made public.

You all know, and some of you, Gentlemen, have perhaps already had the opportunity to be convinced of the fact that after fifteen years of costly work and perseverance, Mr. Daguerre has finally succeeded in discovering a procedure that makes it possible to fix the various objects reflected in a camera obscura and also to describe them in four or five minutes, thanks to the power of light drawings, in which objects preserve their mathematical design in their most minute details, and in which the effects of linear perspective, and the decrease of the shadows generated by aerial perspective are rendered to an unprecedented degree of beauty.

We cannot dwell here on the immense usefulness of this invention. But it will be easy to understand what resources, what new facilities it will bring to the study of the sciences; and, as far as the arts are concerned, the services that it will be able to render go beyond all predictions. Designers and painters, even the most skilled, will find a constant object of observation in this perfect reproduction of nature. On the other hand, this procedure will offer them an easy and rapid method for creating collections of sketches and drawings, which could be obtained only with time and effort in making them by hand, and in this case they would be much less perfect. The art of engraving, which consists in multiplying, through reproduction, these figures traced by nature itself, will derive new and important benefits from this discovery.

For the traveller, the archaeologist, the naturalist, Monsieur Daguerre's apparatus will become an object of continuous and indispensable use. It will help them to take note of what they see, without resorting to anyone's hands. In the future each author will be able to compose the geographical part of his work by stopping for a moment in front of the most complicated of monuments, or the broadest view and in this way he will immediately obtain an exact facsimile of it.

Also in the same year, on August 19, Arago revealed the technique for making a daguerreotype, so officially consecrating photography, to a joint meeting of the Academy of Sciences and that of the Fine Arts. On that occasion he explained what applications photography might have for Egyptology with great expectations:

If we had had photography in 1798, today we would have reliable illustrations of what was taken from the scientific community by the greed of the Arabs (sic) and the vandalism of travellers. Only to copy the millions of hieroglyphics that cover the outer part of the monuments of Thebes, Memphis, Karnak and other places would take us decades and legions of draftsmen. Thanks to the daguerreotype, a single person could successfully complete this immense task. Let us therefore give two or three specimens of Daguerre's equipment at the Institut d'Egypte and an unlimited number of hieroglyphics, as they are in reality, will replace those that are now imagined or roughly reproduced' (Arago, 1839). 

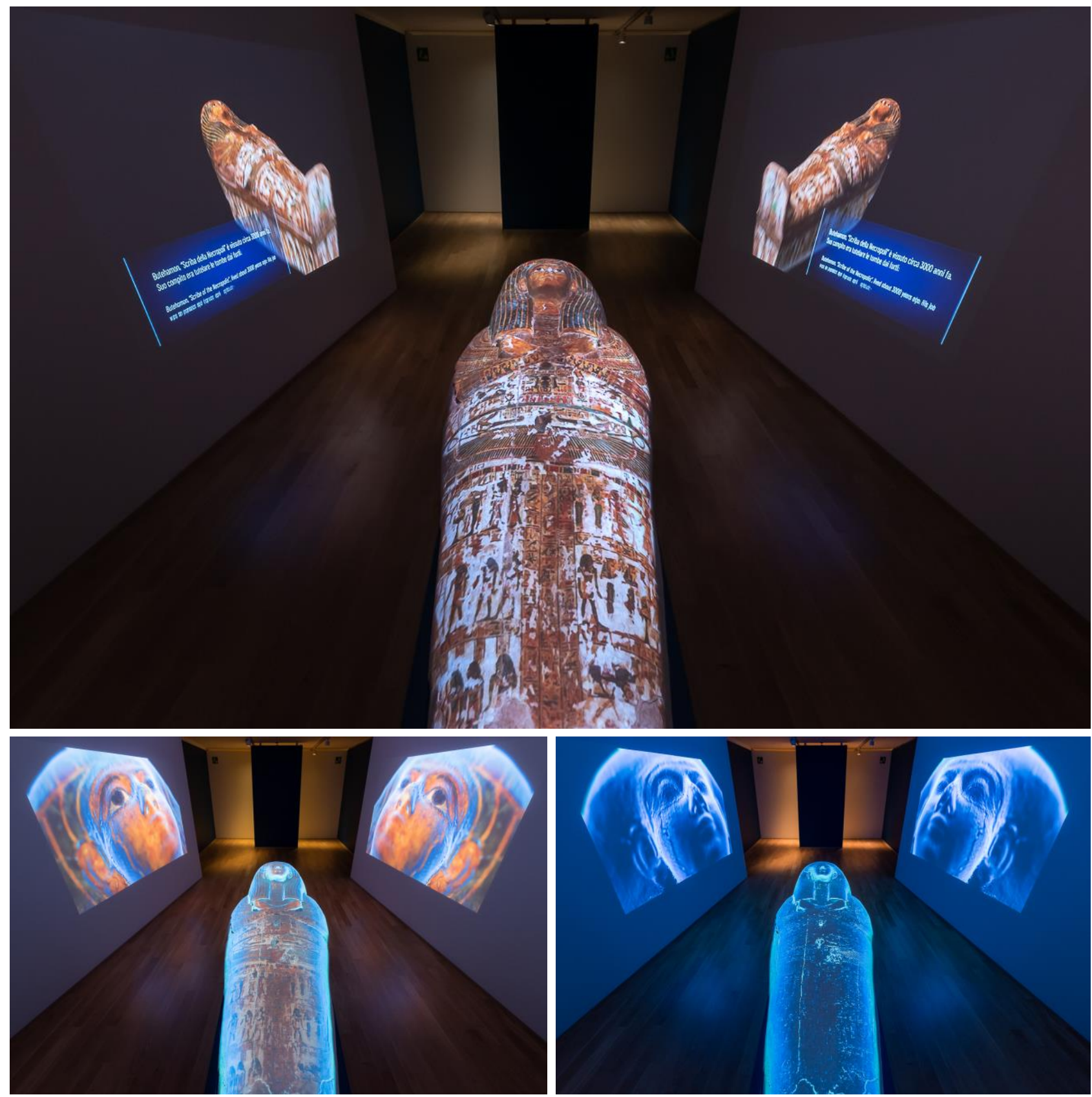

Figure 1. Virtual display of the structure and appearance of the external coffin of Butehamon (Twentieth Dynasty), from the exhibition Archeologia Invisibile, Museo Egizio, Torino, 2019 (photograph by Museo Egizio, Torino).

It is certainly undeniable that photography has changed our ability to represent the world and contributed to the dissemination of knowledge. After one hundred and eighty years from its invention, however, we must note that the documentation of the hieroglyphics that cover the monuments of ancient Egypt is by no means yet complete and, although photography has proved to be a very important aid, the epigraphist's work of drawing and interpretation continue to be fundamental.

Today we find ourselves immersed in the so-called digital revolution that has already profoundly transformed our cognitive approach and the way we work. In the archaeological field, photogrammetry and 3D modelling enable archaeologists to document the whole excavation process and to reconstruct contexts even after their removal.
We can reproduce a sarcophagus with sub-millimetric precision, recording all the phases of its production and reuse (figure 1).

Non-invasive diagnostic imaging allows us to peer into a stillsealed vessel and virtually unwrap mummies (figures 2 and 3). Detailed analyses now give scholars the opportunity to observe the fibres of a papyrus, facilitating the reconstruction of ancient documents.

Digital communication also enables us to create virtual work environments in which scholars from around the world can work together and compare their data. All this facilitates and accelerates the work of the philologist.

So does this mean that the role of the humanist's role is becoming subordinate? 


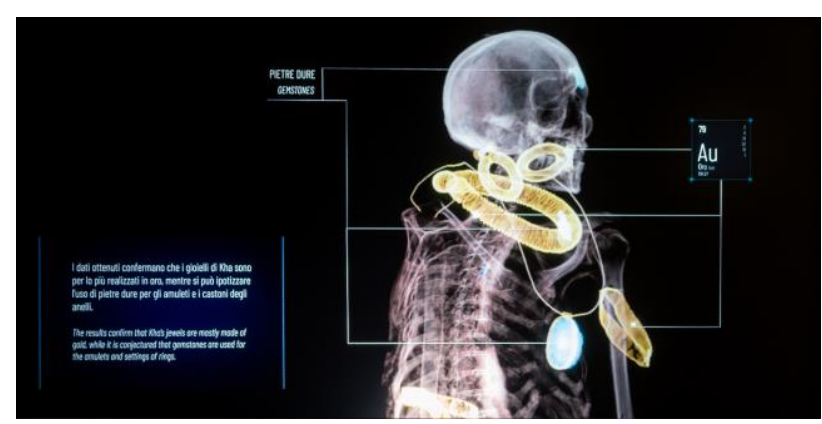

Figure 2. Virtual unwrapping of the mummy of Kha

(Eighteenth Dynasty), from the exhibition Archeologia Invisibile, Museo Egizio, Torino, 2019 (photograph by Museo Egizio, Torino). rethinking the role that museums can have in the future we must at the same time remember the main reason why they were founded, namely to be the place where objects from the past could be preserved. And, despite all the changes we have gone through, it is undeniable that the core of the museum experience is still that of being before artistic products, archaeological documents or the records of social history.

The changes will continue. We will devise different organisational and architectural solutions that will respond more fully to contemporary needs. There will certainly also be new forms of cultural consumption. Our task will always remain, however, to improve the visual, aesthetic and intellectual experience of every visitor before an artefact from the past, seeking to provide all the information necessary to enrich the comprehension of it. The future of museums is, as it has always been, research.

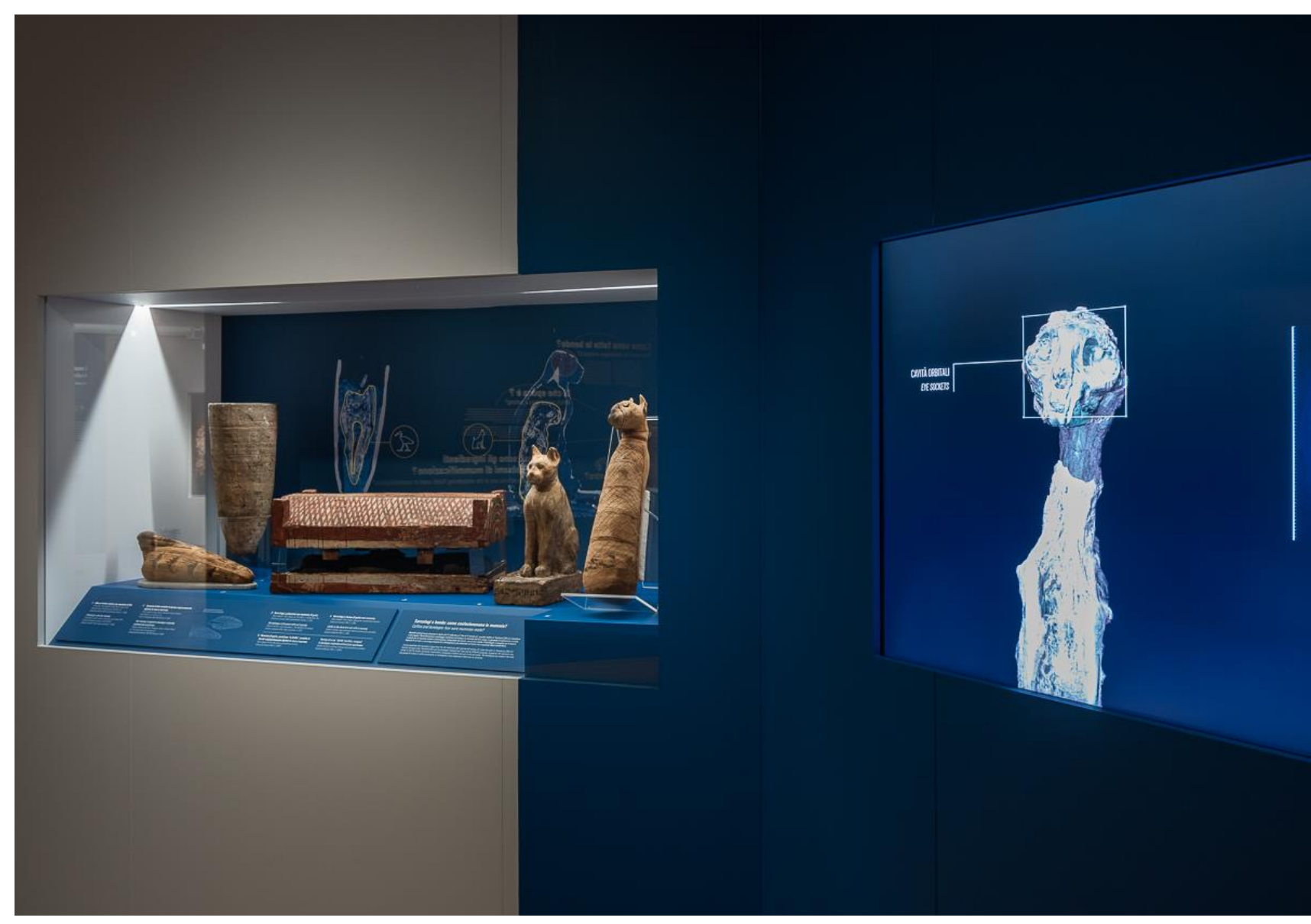

Figure 3. Different types of animal mummies and virtual unwrapping of a cat mummy (cat. 2348/1), from the exhibition Archeologia Invisibile, Museo Egizio, Torino, 2019 (photograph by Museo Egizio, Torino).

Quite the contrary. The data supplied to us is ever more detailed and complex and requires an even more profound level of interpretation (Amselle, 2017).

The scientist and the humanist must increasingly work closely together to try to unravel the complexity of the contemporary world. An ever more profound collaboration that goes beyond the dogmatism of individual fields of knowledge, with the definition of a shared semantics and the development of a true multidisciplinary approach are the only method we have to cope with the challenges of the future (DeMarrais, Gosden, Renfrew, 2004).

And in this, what will the museum's role be? Are these institutions destined to disappear? We must not forget that in

\section{ACKNOWLEDGEMENTS}

This text is the English translation of the essay 'La biografia degli oggetti. Rivoluzione digitale e Umanesimo', in AAVV, Archeologia Invisibile (catalogue of the exhibition 'Archeologia Invisibile', Museo Egizio, Torino, 12 March 2019 - 6 January 2020). Panini, Modena, 14-20.

\section{REFERENCES}

Amselle, J. L., 2017. Il museo in scena. L'alterità culturale e la sua rappresentazione negli spazi espositivi. Meltemi, Milano. 
Arago, F., 1839. Séance du 19 août 1839, in Compte rendu des séances de l'Académie des sciences, IX, 257.

DeMarrais, E., Gosden, C., Renfrew, C., 2004. Rethinking Materiality: The Engagement of Mind with the Material World. McDonald Institute, Cambridge.

Dobres, M. A., Robb, J., 2009. Agency in Archaeology. Routledge, London.

Heidegger, M., 1971. Poetry, Language, Thought. Harper, London.

Hodder, I., 2012. Entangled. An Archaeology of the Relationships Between Humans and Things. John Wiley and Sons, Inc, Oxford.

Malafouris, A., 2010. How Things Shape the Mind, a Theory of Material Engagement. MIT Press, Cambridge.

Malafouris, A., Renfrew, C., 2010. The Cognitive Life of Things. Recasting the Boundaries of the Mind. McDonald Institute, Cambridge.

Meskell, L., 2004. Object Worlds in Ancient Egypt: Material Biographies Past and Present. Berg Publishers, Oxford.

Miller, D., 2005. Materiality. Duke University Press, Durham.

Renfrew, C., Bahn, P., 2016. Archaeology. Theories, Methods and Practice. Thames \& Hudson, London.

Vegetti, M., 2018. Il potere della verità. Saggi platonici, Carocci, Roma. 